\title{
NARRATIVAS AUTOBIOGRÁFICAS: ENTRE LEMBRANÇAS, EXPERIÊNCIAS E ARTEFATOS
}

\section{LUIZ CARLOS PINHEIRO FERREIRA}

Universidade de Brasília

RESUMO O artigo compartilha reflexões acerca da minha pesquisa de doutorado, concluída no Programa de Pós-Graduação em Arte e Cultura Visual da Faculdade de Artes Visuais da Universidade Federal de Goiás [2015]. Utilizo como recorte fragmentos narrativos que evocam artefatos da época de infância: um acordeão e uma colcha de retalhos. Tais artefatos subsidiam lembranças circunscritas por experiências de um percurso autobiográfico e narrativo, que tenciona um viés na contemporaneidade, suscitando outras formas de compreender o processo de formação subjetiva que apurou o apreço pela arte e, consequentemente, minha formação e atuação no âmbito da docência em artes visuais. Esse percurso implica um olhar sobre diferentes temporalidades, articulado como possibilidade de narrar experiências próprias, provocar a abertura de trilhas teóricas e metodológicas relacionadas com as descobertas de uma escavação arqueológica de si.

Palavras-chave: Narrativa. Autobiografia. Experiência. Artefato.

AUTOBIOGRAPHIC NARRATIVES: BETWEEN MEMORIES, EXPERIENCES AND ARTEFACTS

In this article, I share reflections from my $\mathrm{PhD}$ research, conducted at the graduate program of the faculty of Art and Visual Culture at the Universidade Federal de Goiás [2015]. I use as a research frame fragments of narratives evoking artefacts from my childhood: an accordion and a patchwork quilt. Such artefacts evoke memories based on experience. Written as an autobiographic narrative, anchoring the article in contemporary times thus provokes other ways of understanding the process of subjective formation of an appreciation for art and, consequently, my training and performance in the field of teaching the visual arts. This pathway implies different temporalities, articulating the possibilities to narrate one's own experiences, provoking the opening of theoretic and methodological ways related to findings from an archaeological excavation of the self.

Keywords: Narrative. Autobiography. Experience. Artefact. 


\section{NARRATIVAS AUTOBIOGRÁFICAS: ENTRE LOS RECUERDOS, EXPERIENCIAS Y ARTEFACTOS}

Este artículo comparte reflexiones sobre mi investigación doctoral, terminado en el Programa de Posgrado en Arte y Cultura Visual de la Faculdade de Artes Visuais de la Universidade Federal de Goiás [2015]. Uso como recorte fragmentos narrativos que evocan los artefactos del período de la infancia: un acordeón y una colcha patchwok. Tales artefactos subvencionan recuerdos circunscritas por las experiencias de un viaje autobiográfico y narrativa, que propone un sesgo en la época contemporánea, dando lugar a otras formas de entender el proceso de formación subjetiva que encontró el aprecio por el arte y, en consecuencia, mi formación y actuación docente en el campo de las Artes Visuales. Este camino implica una mirada en diferentes momentos, como la capacidad articulada para narrar sus propias experiencias, provocar la apertura de pistas teóricos y metodológicos relacionados con los resultados de una excavación arqueológica de si.

Palabras clave: Narrativa. Autobiografia. Experiencia. Artefacto.

\section{Apresentação: perguntas inquietantes}

O que representa a arte na vida dos sujeitos? Como a arte pode ser significada a partir de experiências estéticas vivenciadas durante a infância? Como essas experiências influenciam escolhas e trajetórias de vida na atualidade? Ao trazer determinadas reflexões para a arena do texto, utilizo um recorte da minha tese de doutorado ${ }^{1}$ para explicitar as questões norteadoras de um caminho autobiográfico e narrativo. Esse caminho serviu para trilhar um percurso metodológico de investigação, marcado por angústias, inquietações e descobertas acerca da minha relação com a arte e,

1 Tese de doutorado: “Mo(vi)mentos Autobiográficos: historiando fragmentos narrativos de experiências de vida docente e discente em artes visuais", defendida no Programa de Pós-Graduação em Arte e Cultura Visual da Faculdade de Artes Visuais da Universidade Federal de Goiás, na Linha de Pesquisa: Culturas da Imagem e Processos de Mediação, sob orientação do Professor Dr. Raimundo Martins e coorientação da Professora Dra. Irene Tourinho, em março de 2015. consequentemente, da atuação como professor de artes visuais. Em especial, angústias e inquietações presentes em uma pergunta que perdurou durante minha formação e atuação profissional: como e por que me tornei professor de artes? Esclareço que o percurso de pesquisa, elaboração e escrita da tese de doutorado foi determinante para compreender com mais propriedade algumas escolhas enredadas por um contexto peculiar. Nesse sentido, coloco em voga aspectos circunscritos por lembranças e artefatos, particulares e norteadores desse percurso autobiográfico e narrativo, que tenciona um viés na contemporaneidade, justamente por abarcar sutilezas advindas de uma atualidade que se faz necessária para compreender caminhos, atalhos e a própria profissão docente, no campo das artes visuais. 
Narrativa, arte e

\section{contemporaneidade: possiveis implicações}

O texto acontece mediante a implicação com os conceitos de narrativa, arte e contemporaneidade. Esses conceitos fazem parte de um percurso de vida e de formação, como também, contextualizam lembranças, artefatos e experiências. Alimentam uma perspectiva particular que interessa tanto a minha vida pessoal e profissional quanto à busca pelo conhecimento de si. Foi a partir de uma investigação de caráter autobiográfico e narrativo que nasceu o interesse por um caminho que descortina aspectos relacionados com a época da infância. Nesse caminho, duas experiências ganham destaque na proposição do texto, porque foram relevantes para compreender escolhas e percursos. Experiências peculiares que delinearam o entendimento e o apreço à arte e, consequentemente, minha entrada no magistério. Uma delas está relacionada a um objeto familiar, o acordeão que pertenceu ao meu pai e que remete ao universo da música. A outra refere-se às lembranças que apontam para o momento em que experimento a colcha de retalhos tecida pela minha avó materna. Tanto o acordeão como a colcha de retalhos representam artefatos emblemáticos e configuram uma temporalidade particular da infância. Essa lembrança arraigada de afetividade levou-me a pensar nas visualidades presentes no cotidiano da infância, no que condiz com a sua potência enunciadora de sentidos e significados para o campo da narrativa autobiográfica. Saliento que essa possibilidade de revisitar os escritos da tese de doutorado, a partir da implicação dos conceitos de "narrativa, arte e contemporaneidade", conforme proposto pelo dossiê, provocou instigantes reflexões. Sobretudo, em virtude de um posicionamento que considera, de acordo com o pensamento de Gi- roux (1997), que um projeto ou estudo não está totalmente pronto, pois o mesmo pode ser lido e ressignificado de acordo com o momento presente, a partir de um olhar crítico e criativo. Dessa forma, o momento da escrita favorece tanto pensar e compartilhar as afetividades experienciadas na infância, a partir dos artefatos, quanto uma possibilidade de reposicionar-me sobre a vitalidade de uma investigação que pode, alhures, apresentar facetas ainda encobertas, com o objetivo de apontar outras formas de narrar e interpretar experiências.

A implicação dos conceitos de narrativa, arte e contemporaneidade, no decorrer do texto, acontece mediante uma perspectiva que mapeia um olhar sobre diferentes tempos e espaços, articulados a partir de lembranças e como possibilidade de narrar as próprias experiências. Desse olhar sobre si mesmo, procuro subsídios para pensar sobre experiências e artefatos marcantes, capazes de provocar a abertura de trilhas relacionadas a descobertas, em uma escavação arqueológica de si. 0 conceito de arte surge numa vertente que privilegia, entre outros caminhos, a noção de arte a partir da experiência cotidiana e particular, com o acordeão do meu pai e com a colcha de retalhos tecida pela minha avó materna. 0 lugar da arte e da expressão artística estava permeado de nuanças, até então, desconhecidas conceitualmente na época da infância. Seu sentido residia no divertimento, na brincadeira e, também, na tentativa de construir enlaces afetivos. 0 contemporâneo ocorre mediante o entendimento da sua amplitude e atualidade, com o tempo da narrativa, ou melhor, do fragmento narrativo, ${ }^{2}$ que traça uma escrita narrativa relacionada aos momentos da própria vida e das experiências. Nesse ponto, o fragmento narrativo permite romper com as amarras presentificadas em acontecimentos remotos e re-

2 Os fragmentos narrativos foram utilizados na tese de doutorado como enunciadores de experiências e lembranças advindas da minha história de vida. 
centes, perfazendo relações entre lembranças e cenas vividas, numa perspectiva que apresenta o contemporâneo como sendo "uma singular relação com o próprio tempo, que adere a este e, ao mesmo tempo, dele toma distância [...]" (AGAMBEN, 2009, p. 99).

\section{Lembranças e experiências: 0 universo da arte}

Antes de apresentar o contexto dos fragmentos narrativos relacionados com um acordeão e uma colcha de retalhos, saliento outra questão determinante e sempre inquietante na minha vida: o interesse pela arte. Sempre considerei que essa inclinação era resultado de uma influência da época da escola, sobretudo pelo domínio do desenho e pelo prazer de fazê-lo diariamente. Mesmo antes de ingressar na escola eu já fazia desenhos em casa. 0 meu cotidiano era preenchido por cenas, imagens, formas e cores, que ficavam impregnadas em minha mente. A escola foi o lugar onde aprendi a significá-los.

Nasci numa família que, apesar da falta de estudo formal, sempre teve algum envolvimento com o universo das artes. Meu pai gostava de carnaval, dos festejos de rua. Participava das antigas e tradicionais festas de padroeiros, onde tudo era enfeitado segundo a tradição do santo e, também, gostava de tocar acordeão. Minha mãe sempre foi muito caprichosa, fazia crochê, tricô, bordados e, até hoje, mantém seu gosto por atividades manuais. Meus irmãos, na época de escola, realizavam trabalhos impecáveis na aula de educação artística e em casa eram exímios fazedores de pipas e outras "artesanias". Então, por que essa inquietação sobre a minha escolha pelo campo das artes? Entendo que, no meu caso, existe um esforço significativo para rememorar lembranças que são imprescindiveis para ressignificar minha consciência de si, no sentido de entender como determinadas experiências da infância foram significadas como dispositivos que permitiram o endereçamento para a arte.

\section{Reminiscências da infância: acordeão como (arte)fato}

0 questionamento de onde vem o meu interesse pela arte, pela profissão docente, foi atenuado a partir de algumas elaborações, sobretudo aquelas que apontam lembranças da infância. Essas lembranças funcionam como dispositivos que capturam e orientam gostos e inclinações estéticas. 0 acordeão representou, na época de minha infância, um artefato peculiar, porque remetia ao universo da arte e da música. Atualmente, guardo o acordeão do meu pai com muito zelo, uma forma de manter na minha memória o seu gosto pela música (Figura 1). Talvez essa tenha sido uma forte influência na minha infância, despertando em mim o desejo pela apreciação daquilo que é artístico. Hoje, preservo este artefato como uma relíquia integrada ao mundo da casa, como representação de um tempo que passou. Todavia, a lembrança e a admiração permanecem imaculadas e registradas nas reminiscências de uma vida de menino.

Figura 1: Acordeão utilizado pelo meu pai.

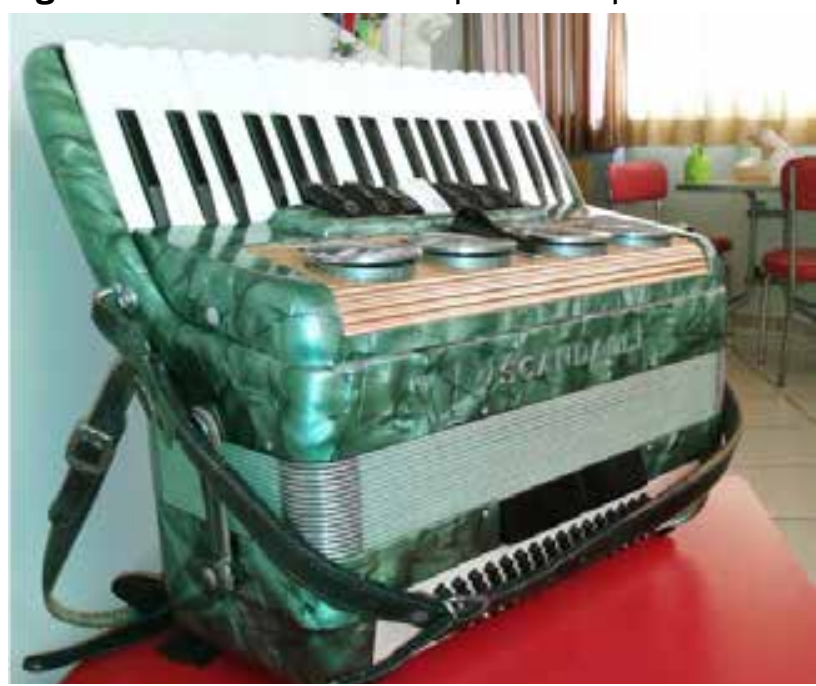

Fonte: Acervo do autor. 
A imagem do meu pai tocando o acordeão faz parte de um lugar particular, de uma lembrança tênue no tempo. Um tempo que, segundo Bosi (2003, p. 36), abre espaço para uma "força subjetiva ao mesmo tempo profunda e ativa, latente e penetrante, oculta e invasora", prestes a lançar no tempo presente resquícios desse lugar do passado, mas ainda presente nas lembranças e recordações da infância. Esse tempo carregado de força subjetiva e profunda, conforme aponta Bosi (2003), acontece mediante a narrativa que permeia os fragmentos. A narrativa acentua a importância das lembranças, aguça a capacidade de reviver na memória momentos relevantes, sobretudo para resgatar minúcias imprescindiveis ao conhecimento de si. Além disso, essas lembranças permitem compreender o meu interesse pelo campo das artes; e, também, significar com mais nitidez, tanto do ponto de vista pessoal quanto profissional, minha relação com a arte, com meu processo formativo e autoformativo.

0 fragmento narrativo acontece como algo que possibilita compreender minha experiência associando-a às relações entre presente e passado. Como um arqueólogo que escava os escombros para encontrar resquícios, pedaços e fragmentos que possam, metaforicamente, ajudar-me a reconstruir o edificio simbólico que representa o sujeito. Os fragmentos narrativos exercem essa tarefa de reconstruir contextualmente o tempo e o espaço acerca das ações vivenciadas, sobretudo com outras pessoas, em determinado tempo e lugar. Nesse sentido, a narrativa, em consonância com o pensamento de Martins e Tourinho (2009, p. 4):

[...] é uma forma de compreensão da experiência. Ela tem como objeto de estudo histórias vividas e contadas que possibilitam mediações entre pensamento e ação, contexto e circunstância, presente e passado, mapeando os elementos que constroem, tecem significados entre a história individual e a história social dos indivíduos.
Martins e Tourinho (2009), ao apontarem as características da pesquisa narrativa, consideram que os deslocamentos epistemológicos, ou seja, os relatos narrativos ganham força quando envolvem o leitor/sujeito, persuadindo-o e seduzindo-o a se colocar dentro da experiência narrada. Nesse sentido, tenho como objetivo apresentar, mesmo que parcialmente, lembranças e aprendizagens dessas experiências vividas a partir de fragmentos de narrativas pessoais, que funcionam como fendas que abrem passagens e anunciam caminhos.

\section{Fragmento narrativo: acordeão}

o acordeão ficava guardado dentro de um baú. Uma relíquia trancada a sete-chaves pelo meu pai. Somente nos dias de "cantoria", como dizia minha mãe, era possivel observar tamanha beleza. Um instrumento gigante perante minha figura de menino. Eu olhava fascinado para o brilho que aquele artefato imprimia na minha imaginação. Era bonito de ver e ouvir. A cantoria acontecia sempre que um amigo aparecia para visitar a família. Meu pai, entusiasmado com a conversa, pegava logo o instrumento $e$ começava a tocar para entreter os amigos e a família. Era um momento especial, onde as dificuldades da vida eram trocadas por momentos de alegria e felicidade. A sonoridade derivada do instrumento, a partir dos dedos do meu pai sobre as teclas, em preto e branco, conjugavase ao movimento do seu corpo, que acompanhava o som. Aquela imagem do meu pai com o acordeão diferenciava-se da imagem do meu pai durante o cotidiano da casa. Sua rudeza diária parecia desaparecer. Surgia um olhar diferente para a vida, mais prazeroso e harmonioso com a sua existência. Essas percepções estão presentes nas lembranças da infância $e$ ganham sentido a partir das minhas reflexões e elaborações. Um movimento que busca nas reminiscências cotidianas da infância certa efervescência, procurando algo que possa in- 
teressar tanto à memória quanto à minha história de vida. Algo que possa dizer da vida, do passado, daquilo que ficou marcado na escritura do mundo, conforme alerta Benjamin (1995). Lembro-me que houve um dia em que meu pai não colocou o acordeão dentro do baú, depois de usá-lo. Por pressa, esquecimento ou conveniência, ele foi deixado do lado da cama dos meus pais, quase que escondido entre a parede e a mesinha de cabeceira. Essa foi a minha oportunidade de observar em detalhes aquele artefato. Cheguei a pegá-lo no colo para sentir o seu peso e dimensão. O medo era enorme, pois poderia acontecer algum incidente, mas, ao mesmo tempo, uma fascinação tomava conta de mim. A estripulia não poderia deixar de acontecer! Tomei coragem e "vesti" o instrumento, colocando as alças e segurando bem firme, enquanto permanecia sentado na beirada da cama. $O$ ato de vestir o acordeão desvelou um sentimento de pertencimento ao seu significado musical e artístico. A sensação de sentir o acordeão colado ao meu corpo construía ressonâncias na minha tessitura subjetiva. Mesmo sem entender a instância conceitual no tocante a sua potência instrumental, eu percebia que aquele artefato possuía um valor imensurável para o meu pai. Por isso, os sentimentos de medo e fascinação eram tão próximos, naquele momento. Eu sabia que estava fazendo algo que não devia. Ao mesmo tempo, a curiosidade venceu o medo e fui levado a apertar uma das teclas, acionando um leve som que permanece presente até hoje em minha lembrança, marcado na minha escritura do mundo representada simbolicamente pela infância.

\section{Reminiscências da infância: colcha de retalhos como dispositivo criativo}

Minha lembrança da infância com a colcha de retalhos produzida pela minha avó materna faz-me refletir sobre os sentidos dessa experiência, especialmente como forma de significar a minha relação com o universo da criatividade. As lembranças da infância, nesse sentido, devem sua existência a um processo de deslocamento (FREUD, 1996a). Nesse contexto a respeito do deslocamento das lembranças, reforço que foi através do percurso de análi$\mathrm{se}^{3}$ que recuperei determinadas lembranças e impressões significativas relacionadas com a época da infância. Um movimento arqueológico de investigação que permitiu acessar questões que diziam respeito ao afeto e às boas recordações de uma época determinante da minha formação subjetiva. Esse movimento de atenção para com a vida compreende justamente a significação dessa vida, por que "na memória, a pessoa realça e acentua os momentos de sua vida que foram experimentados como significativos, ao passo que os outros caem no esquecimento" (DILTHEY, 2010, p. 245). Nesse aspecto, a colcha de retalhos pressupõe uma experiência significante no contexto da minha formação, um dispositivo que envolve aprendizado, afetos e uma habilidade que se organiza e ganha unidade em função da diferença que caracteriza os formatos, cores e texturas dos pedaços de tecidos.

A colcha de retalhos torna-se um artefato emblemático porque constrói sentidos para a vida, para um entendimento sobre o que constitui a criatividade, justamente por considerar a complexidade que abarca os domínios social, cultural, psicológico e educacional (KINCHELOE, 2007) da aprendizagem, envolvendo tanto a vida quanto o seu percurso de formação estética. Refletir sobre a compreensão acerca da vida e da formação confere um conhecimento autoimplicativo, ou seja, um modo de conhe-

3 Desde 2004 realizo um percurso de análise na perspectiva lacaniana, justamente por considerar pertinente à elaboração dos sintomas, conceitos e situações reveladas pelo inconsciente, que fazem parte da minha constituição como sujeito e, desse modo, passivel das sintomáticas da existência humana. 
cer hermenêutico que, ao mesmo tempo em que amplia o conhecimento das coisas, também proporciona um saber sobre nós mesmos (SOUZA; FORNARI, 2012). Essa compreensão, entendida metaforicamente como colcha de retalhos, fragmentos de experiências e narrativas que buscam autenticar nossa relação dialógica com o mundo. Ao lidar com a confecção da colcha de retalhos, minha avó aprendeu a lidar com as diferenças que encontrava nos pedaços de tecidos, fazendo uma pesquisa intuitiva acerca das possibilidades dos retalhos: pequenos, médios, grandes, ásperos, lisos, estampados, quadriculados, floridos, bordados, de algodão, de seda, de cetim, de flanela, de veludo, enfim, uma multiplicidade significativa de diferenças. Percebi essa diferença ao observar e imaginar histórias a partir da colcha de retalhos que cobria a cama do quarto da minha avó, da mesma maneira como aprendi a observar seu domínio e perspicácia, ao confeccionar de forma tão afetuosa aqueles artefatos (Figura 2).

Figura 2: Detalhe da colcha de retalhos. Presente de minha avó, que guardo com zelo.

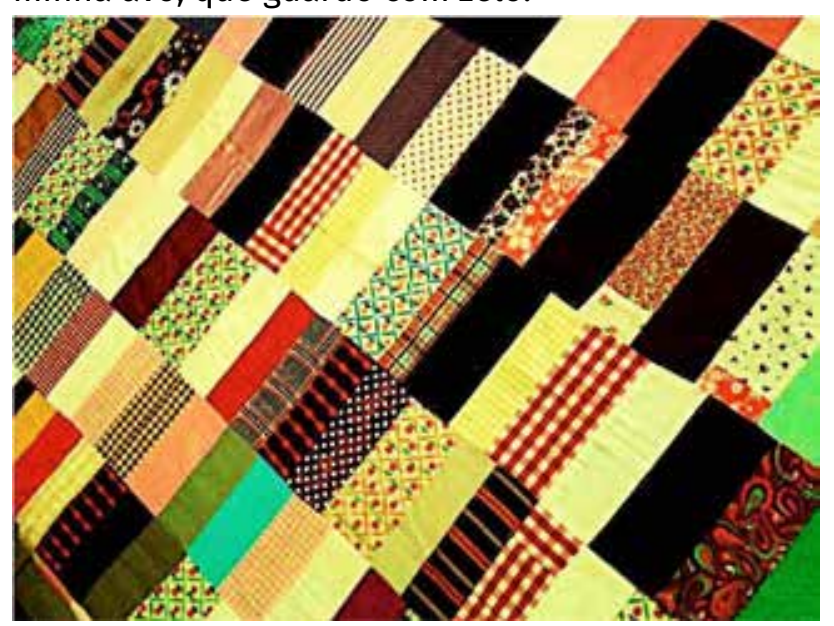

Fonte: Acervo do autor.

\section{Fragmento narrativo: colcha de retalhos}

Guardo lembranças da convivência com a minha avó materna até os doze anos, quando ocorreu o seu falecimento. Vovó Rosa era uma senhora muito doce, com um cheirinho característico de leite de rosas. Visitá-la era um prazer porque representava a oportunidade de sair do meu mundo e observar, respirar e viver outros ares. Nos domingos, vovó Rosa sempre nos recebia com bolos deliciosos acompanhados do cafezinho com leite que não podia faltar. Minha irmã, minha mãe e eu ficávamos bastante tempo em sua casa, tempo suficiente para que eu pudesse ir ao seu quarto e ficar deitado em sua cama. Foi num desses momentos, sozinho no quarto da minha avó, que passei a observar a colcha que ela usava na cama. Eu já tinha visto inúmeras vezes o processo da costura de retalhos que vovó fazia. Era fantástico o modo como ela costurava e organizava aqueles retalhos de tecidos que, à primeira vista, não tinham serventia, como ela mesma dizia. Ela cortava e ajustava os diferentes tipos de tecidos em uma caixa para depois emendá-los um a um até formar uma colcha. Era um processo demorado que dependia dos retalhos e de uma boa dose de paciência. Muitas vezes ajudei na arrumação dos retalhos tentando separá-los por cor ou tamanho. Minha vó não gostava e quando percebia meu esforço exclamava: - Meu filho, não é pra fazer isso! É só colocar na caixa esticando os retalhos, não quero que fiquem separados desse jeito. Na hora da costura, vou juntando tudo e no final a colcha fica pronta. Como juntar diferentes tecidos, cores, estampas e texturas numa mesma colcha, de forma harmoniosa? Na minha concepção de criança aquele modo de fazer a colcha não daria certo. Depois de algum tempo a colcha ficava pronta e os pedidos eram sempre numerosos: filhos, netos $e$ agregados, todos queriam ter uma colcha da vovó Rosa. Em sua cama havia uma colcha antiga, usada especialmente aos domingos, para enfeitar o quarto. Foi naquele cenário, deitado na cama, que pude perceber como diferentes tipos de retalhos podiam configurar um todo, apesar das singularidades de cada fragmento 
de tecido. Essas situações e cenários, segundo Martins e Tourinho (2009), se revelam por meio da narrativa, inscrevendo-se em experiências e aprendizagens que têm como referência aquilo que cada sujeito vivenciou. Naquela época, eu não conseguia compreender porque a colcha de retalhos me provocava e como poderia suscitar lembranças na atualidade. Lembro que a minha intenção era apreciar o colorido da colcha. Era linda! Por vezes, passava horas deitado na cama da vovó observando cada pedaço da colcha. Eu imaginava uma estória para cada retalho, como se cada um ganhasse vida própria. Era fácil construir minhas estórias na imaginação e depois desenhá-las. Ao mesmo tempo, ficava intrigado e me questionava como aquelas estórias, representadas por retalhos de tecidos, formas, cores estampas $e$ texturas tão diferentes, podiam estar juntas num espaço delimitado por linhas de costura que, como num passe de mágica, faziam com que aquele todo ganhasse consistência. Minhas estórias também funcionavam, apesar da diversidade e singularidade de cada personagem que criava. Hoje, percebo que aquela experiência com a colcha de retalhos deixou marcas afetivas na minha constituição subjetiva, sendo primordial para me ajudar a compreender como e por que estabeleço relações com os fragmentos narrativos que sustentam minhas memórias de infância.

As lembranças providas a partir desses artefatos representaram vestígios de experiências determinantes para o contexto da minha formação. E, mais tarde, repercutiriam num olhar curioso sobre a vida e a arte. Nesse aspecto, interrogo-me novamente acerca da possibilidade de diálogo em relação às experiências contidas no cotidiano, em sua dinâmica permanentemente inventada para permitir o fluxo da vida, da criatividade e da invenção (CERTEAU, 1994). O que possuem em comum tais lembranças? Como as mesmas podem de- sencadear maneiras de pensar afetos, experiências e aprendizagens construídas ao longo da vida? Penso que ao rememorar essas lembranças da infância, o meu olhar curioso sobre a vida e a arte amplia o sentido da experiência e contribui na legitimação do valor epistemológico e existencial presente nos momentos que a vida proporciona. Por isso, ao definir o caminho do texto, optei por acontecimentos peculiares que marcaram minha infância, numa perspectiva que considera a escrita da narrativa como uma arte de evocar e de lembrar, capaz de remeter "[...] o sujeito a eleger e avaliar a importância das representações sobre sua identidade e práticas formativas que viveu, de domínios exercidos por outros sobre si, de situações fortes que marcaram escolhas e questionamentos sobre suas aprendizagens" (SOUZA, 2006, p. 61). Nesse aspecto, reitero novamente a oportunidade de escrever este texto, na tentativa de lançar um outro olhar sobre os acontecimentos do passado, para suscitar outras formas de compreender o processo de formação subjetiva que me levou ao campo da arte e da docência.

\section{A escrita narrativa: experiências de vida e formação}

Ao refletir sobre as lembranças da infância, das memórias presentificadas no cotidiano da casa e das narrativas construídas a partir daquilo que foi vivido e experienciado em minha vida de menino, percebo quão importante foi o processo que me constituiu, tanto no aspecto da minha formação quanto no tocante à minha autoformação como sujeito. Souza (2006) apresenta apontamentos pertinentes para arregimentar proposições que constituem possibilidades de pensar sobre o processo do conhecimento de si. Nesse sentido, entendo o conhecimento de si a partir da proposição de narrativas que aportem experiências mar- 
cantes, inscritas na minha tessitura de vida, quando

[...] a escrita da narrativa remete o sujeito a uma dimensão de auto-escuta, como se estivesse contando para si próprio suas experiências e as aprendizagens que construiu ao longo da vida, através do conhecimento de si. E com base nessa perspectiva que a abordagem biográfica instaura-se como um movimento de investigação-formação, ao enfocar o processo de conhecimento e de formação que se vincula ao exercício de tomada de consciência, por parte do sujeito, das itinerâncias e aprendizagens ao longo da vida, as quais são expressas através da metarreflexão do ato de narrar-se, dizer-se de si para si mesmo como uma evocação dos conhecimentos construídos nas suas experiências formadoras (SOUZA, 2006, p. 14).

O apontamento de Souza remete ao processo de investigação-formação e autoformação de sujeitos. Esse processo interessa-me pelo aspecto (auto)biográfico, porque, ao produzir uma escrita narrativa a partir de fragmentos que contam e recontam lembranças, acredito na dimensão propositiva que o mesmo implica, sobretudo pelo viés da autoescuta. Essa escrita narrativa imbrica-se a um processo permanente de rememorar, de deixar vir à tona algo que completa o sujeito e permite a compreensão de situações, de histórias, de lembranças e episódios guardados na memória. Nesse sentido, considero que o "[...] ato de narrar tem como propriedade o estabelecimento de percepções confiáveis da memória" (GINZBURG, 2012, p. 116). Por esta razão, o campo da memória encontra reconhecimento, por representar arcabouço "confiável" que privilegia os encontros entre aquilo que busco nas lembranças da infância para compreender, na atualidade, a partir da escrita narrativa, os caminhos percorridos durante o meu processo de formação pessoal e profissional.

A escrita narrativa acontece como “[...] o melhor modo de representar e entender a ex- periência" (CLANDININ; CONNELLY, 2011, p. 48), justamente pelo potencial enunciativo articulado ao campo da memória. Tanto a memória como a experiência, ambas funcionam como dispositivos capazes de suscitar recordações que servem como desenho para representar e entender o que sou. Seria impossivel considerar, conforme aponta Souza (2006), a dimensão da autoescuta, sem levar em conta o encontro entre esse eu que conta para si mesmo suas experiências a partir de um esforço de rememorar. Ao abordar a experiência como processo pertinente ao contexto das histórias vividas e contadas, os estudos de Clandinin e Connelly (2011) concentram-se no campo conhecido como pesquisa narrativa. Esse campo, segundo Martins e Tourinho (2009), a partir dos anos de 1980, tornou-se tema de interesse acadêmico, repercutindo nos departamentos de literatura, psicologia e sociologia. Os autores alertam para o fato de que a pesquisa narrativa se expandiu para áreas como a cultura, educação, cinema, teatro e artes visuais. Nesse sentido, "aos poucos, a narrativa vem se tornando objeto de estudo, ganhando espaço em diferentes disciplinas, influenciando a prática da pesquisa e, consequentemente, os debates acadêmicos" (MARTINS; TOURINHO, 2009, p. 1). Essa perspectiva, que leva em conta a disseminação da pesquisa narrativa para outras áreas, visa contribuir para o deslocamento de olhares que ainda acreditam na neutralidade do sujeito na produção do conhecimento, ignorando a dimensão subjetiva presente e atuante na percepção da realidade e dos fatos.

Para Clandinin e Connelly (2011), os estudos em pesquisa narrativa têm avançado em notoriedade e confiabilidade, no mundo da pesquisa qualitativa, justamente por assegurarem a captura das dimensões pessoais e humanas que, de algum modo, não podem ser quantificadas como fatos e dados numéricos. Os fatos e dados perfazem um contexto de vida assegu- 
rando que o sujeito se torne, ao mesmo tempo, sujeito e objeto da pesquisa, considerando as subjetividades inerentes ao processo de investigação.

Ao conceber os fragmentos narrativos presentes no texto como uma possibilidade de abordagem autobiográfica, permito-me interpretar a vida nesse "continuum" vivido em experiências na época da infância. Experiências, em especial, construídas através do convívio familiar, compreendido pelo desafio de interagir com outros sujeitos, lidar com diferenças e particularidades presentes em artefatos que desafiaram minha curiosidade de criança, despertando-me para outros olhares e percepções sobre a vida e a arte. Nesse aspecto, o argumento de Delory-Momberger (2012) reforça, conceitual e metodologicamente, a posição que tenho adotado. Segundo a autora,

[...] a atividade biográfica não fica restrita apenas ao discurso, às formas orais ou escritas de um verbo realizado. Ela se reporta, em primeiro lugar, a uma atitude mental e comportamental, a uma forma de compreensão e de estruturação da experiência e da ação, exercendo-se de forma constante na relação do homem com sua vivência e com o mundo que o rodeia. (DELORYMOMBERGER, 2012, p. 525)

Assim, ao reportar-me à relação estabelecida com a visão de mundo da época de infância, estou construindo estruturas interpretativas de uma experiência vivida, nas quais pessoas e ações ganham significação através de fragmentos narrativos. De acordo com a autora, a utilização dos termos biografia e biográfico não deve ser feita, apenas, para designar a realidade factual do vivido, ou seja, a narrativa biográfica adquire sentido para além das estruturas registradas no papel. A narrativa adquire um sentido simbólico que atravessa as amarras do inconsciente e se projeta para o entendimento de experiências vividas. A narrativa biográfica assume lugar de "repre- sentações e de construções segundo as quais os seres humanos percebem sua existência" (DELORY-MOMBERGER, 2012, p. 525), a ponto dessa narrativa da experiência tornar-se uma escrita que imprime um modo de apreensão e de interpretação da vivência, ao incorporar sua dinâmica, tornando-a uma escrita de si.

A escrita de si, numa perspectiva que permite redesenhar os contornos da sua vida a partir de contextos específicos, também desafia a repensar sua história em contextos narrativos. Nesses contextos reside uma infinidade de possibilidades de narrar fragmentos, resquícios e histórias acerca da temporalidade, projetando-se como difusores de situações vividas e passiveis de serem contadas e recontadas. Esses contextos vividos representam situações que experienciamos e por meio das quais podemos fazer conexões com situações que jamais teríamos imaginado. Nesse sentido, a escrita narrativa tenciona reflexões e argumentações acerca da potencialidade da vida e suas lembranças, como processo autorreflexivo e de interação com o mundo, com outras pessoas e consigo mesmo.

\section{Entre lembranças, experiências e artefatos: implicações entre vida} e arte

Ao rememorar as experiências contidas em artefatos e lembranças, busco sincronizar questões pessoais para elaborar situações da infância que me ajudem a elucidar preferências atuais que considero determinantes para a compreensão das minhas escolhas, especialmente, da história de vida, porque, entendo, em consonância com Ricoeur (2010, p. 420), que, "[...] um sujeito se reconhece na história que ele conta para si mesmo sobre si mesmo". Ao recordar, contar e narrar episódios pontuais no processo de constituição da minha história de vida, tomo consciência das marcas 
que foram determinantes na infância, em especial aquelas que estão definindo minha história como docente e meu "modus operandi" na vida adulta.

Partindo dessa busca por compreender o processo da memória, das marcas deixadas ao longo da trajetória infantil, como rastros de afetos e lembranças que perfazem minha história de vida, sou levado a refletir constantemente sobre esse (eu) sujeito professor, sua identidade e seus entrelaçamentos, pessoal e profissional, que, de acordo com Nóvoa (2007, p. 17), nos colocam "[...] de novo face à pessoa e ao profissional, ao ser e ao ensinar", que não podem ser separados, porque convivem na mesma pessoa. 0 que sou se reflete no que ensino, como produção de significados que legitimam formas particulares de vida (GIROUX, 1997), portanto, o afeto e o conhecimento de si (SOUZA, 2006) tornam-se condição sine qua non para a compreensão da vida pessoal e profissional. Ao pensar e desenvolver uma investigação no âmbito da perspectiva narrativa de viés autobiográfico entendo a necessidade e a urgência de "[...] compreender o fenômeno educativo, especificamente no que tange ao processo de formação e desenvolvimento pessoal e profissional do educador" (SOUZA, 2006, p. 19).

Segundo Freud (1996c), no artigo "Construções em Análise", recordar certas experiências e os impulsos afetivos que elas trazem à tona é invocar, no presente, elementos que o sujeito esqueceu. 0 autor salienta, ainda, que esses sintomas e inibições são consequências de repressões que se constituem ao substituir experiências vividas que o sujeito olvidou. No entanto, acrescenta, o trabalho de recuperação das lembranças pode vir através de fragmentos em sonhos ou, quando o sujeito se entrega à "associação livre" e produz ideias que podem fazer alusão às experiências reprimidas, derivadas de impulsos afetivos recalca- dos (FREUD, 1996b). Nesse sentido, o processo de reviver lembranças e situações da época da infância, como algo que ficou preso por muito tempo na memória, é uma maneira de gerar ou reelaborar relações afetivas e formativas. Por isso, os fragmentos narrativos funcionam como modos de contar a própria história, pois não há experiência humana que não possa ser expressa, contada e recontada na forma de uma narrativa (JOVCHELOVITCH; BAUER, 2011).

\section{Considerações}

A narrativa compreende uma escrita de si, um espaço para biografar-se. A narrativa acontece mediante uma tessitura de fios, retalhos que vão sendo justapostos, formando uma colcha de retalhos materializada a partir de argumentos, ideias e episódios reunidos e contextualizados através das experiências vividas. 0 ato de narrar é dimensionado, especialmente para repertórios da época da infância, trazendo à tona fatos e situações relevantes. Tais fatos e situações constituem um conjunto de fragmentos narrativos, onde há um processo contínuo e reflexivo entre o viver, contar, reviver e recontar de experiências vividas (CLANDININ; CONNELLY, 2011), que tecem uma colcha de retalhos para estampar uma história de vida, silenciosamente permeada de lembranças. As lembranças afetivas inscritas na existência do sujeito com a sua experiência de vida, remetem às questões formativas perante a própria vida e a formação, especialmente quando estas estão atreladas ao processo da narrativa e da biografia como vertentes para pensar o sujeito em formação. De acordo com DeloryMomberger, "[...] a narrativa de vida continua a ser vista como um percurso orientado e finalizado, pelo qual o narrador retraça a gênese do ser no qual se tornou" (2011, p. 337). Desse modo, ao conectar lembranças e afetos, vida e arte, estou rememorando experiências à luz de concepções autorreflexivas que têm pro- 
vocado desdobramentos na minha percepção sobre a vida.

Pensar como ocorre nossa relação com o mundo dos afetos, das lembranças e da memória, representa um desafio. Esse desafio pode ser entrecortado por artefatos que cruzam nossa lembrança com o objetivo de alertar sobre sua relevância. O fragmento narrativo que versa sobre o acordeão revela aspectos surpreendentes acerca do encontro com a arte, sobre minha formação e atuação no âmbito das artes visuais. Permite associações e compreensões sobre o meu interesse pela arte. Do mesmo modo, ao entrever uma colcha de retalhos, na qual cada fragmento de tecido representa diferenças e similarida-

\section{Referências}

AGAMBEN, Giorgio. O que é o contemporâneo? E outros ensaios. Tradução de Vinícius Nicastro Honesko. Chapecó, SC: Argos, 2009.

BAKHTIN, Mikhail. Marxismo e filosofia da linguagem: problemas fundamentais do método sociológico na ciência da linguagem. Tradução de Michel Lahud e Yara Frateschi Vieira. São Paulo: Hucitec, 2004.

BENJAMIN, Walter. Rua de mão única. Traducão de Rubens Rodrigues Torres Filho e José Carlos Martins Barbosa - Obras Escolhidas II. São Paulo: Brasiliense, 1995.

BOSI, Ecléa. 0 tempo vivo da memória: ensaios de psicologia social. São Paulo: Ateliê Editorial, 2003.

CERTEAU, Michel de. A invencão do cotidiano: 1. Artes de fazer. Tradução de Ephraim Ferreira Alves. Petrópolis, RJ: Vozes, 1994.

CLANDININ D. Jean; CONNELLY, F. Michael. Pesquisa narrativa: experiência e história em pesquisa qualitativa. Tradução do Grupo de Pesquisa Narrativa e Educação de Professores ILEEL/UFU. Uberlândia: EDUFU, 2011.

DELORY-MOMBERGER, Christine. Abordagens meto- des, como também o inusitado, sou levado a considerar um repertório inventivo e criativo que permeou minha formação subjetiva. Tais artefatos configuram dispositivos imprescindiveis para o processo formativo, estabelecendo diálogos e reflexões que convidam o sujeito a interrogar-se permanentemente sobre sua história de vida. Nessa proposta dialógica com a vida e a arte (BAKHTIN, 2004), com o mundo dos afetos e das lembranças, o conhecimento surge da interação dinâmica entre o sujeito e sua percepção de si no mundo através de lembranças circunscritas por fragmentos que contam histórias, em diferentes temporalidades formativas e autoformativas.

dológicas na pesquisa biográfica. Revista Brasileira de Educação, v. 7, n. 51, p. 523-536, set./dez. 2012.

Disponivel em: <http://www.scielo.br/pdf/rbedu/ v17n51/02.pdf>. Acesso em: 10 set. 2013.

DELORY-MOMBERGER, Christine. Fundamentos epistemológicos da pesquisa biográfica em educação. Revista em Educação, Belo Horizonte, v. 27, n. 1, p. 333-346, abr. 2011. Disponivel em: <http://www.scielo.br/pdf/edur/v27n1/v27n1a15.pdf>. Acesso em: 10 set. 2013.

DILTHEY, Wilhelm. A construção do mundo histórico nas ciências humanas. Tradução de Marco Casanova. São Paulo: Editora UNESP, 2010.

FREUD, Sigmund. Lembranças da infância e lembranças encobridoras - capítulo IV [1901] In: Sobre a psicopatologia da vida cotidiana. Rio de Janeiro: Imago, 1996a [1900]. p. 59-66. (Edição Standard Brasileira das Obras Psicológicas Completas de Sigmund Freud, v. VI).

FREUD, Sigmund. Lembranças encobridoras [1899] In: Primeiras publicações psicanalíticas. Rio de Janeiro: Imago, 1996b [1893-1899]. p. 285304. (Edição Standard Brasileira das Obras Psicológicas Completas de Sigmund Freud, v. III). 
FREUD, Sigmund. Construções em análise I e II [1937]. In: . Moisés e o monoteísmo, Esboço de psicanálise e outros trabalhos. Rio de Janeiro: Imago, 1996c [1937-1939], p. 273-287. (Edição Standard Brasileira das Obras Psicológicas Completas de Sigmund Freud, v. XXIII).

GIROUX, Henry A. Os professores como intelectuais: rumos a uma pedagogia crítica da aprendizagem. Tradução de Daniel Bueno. Porto Alegre: Artes Médicas, 1997.

GINZBURG, Jaime. A interpretação do rastro em Walter Benjamin. In: SEDLMAYER, Sabrina; GINZBURG, Jaime (Org.). WALTER BENJAMIN: rastro, aura e história. Belo Horizonte: Editora UFMG, 2012. p. 107-132.

JOVCHELOVITCH, Sandra; BAUER, Martin W. Entrevista narrativa. In: BAUER, Martin W.; GASKELL, George. (Orgs.). Pesquisa qualitativa com texto, imagem e som: um manual prático. Tradução de Pedrinho A. Guareschi. Petrópolis, RJ: Vozes, 2011. p. 90-113.

KINCHELOE, Joe. Introdução - O poder da bricolagem: ampliando os métodos de pesquisa. In: KINCHELOE, Joe L.; BERRY, Kathleen S. Pesquisa em educação: conceituando a bricolagem. Tradução de Roberto Cataldo Costa. Porto Alegre: Artmed, 2007. p. 15-37.

MARTINS, Raimundo; TOURINHO, Irene. Pesquisa narrativa: concepções, práticas e indagações. In: CONGRESSO DE EDUCAÇÃO, ARTE E CULTURA, 2., 2009, Santa Maria. Anais... Santa Maria, RS: CEAC, 2009. p. 1-12.

NÓVOA, António. Os professores e as histórias da sua vida In: NÓVOA, António. (Org.) Vidas de professores. Portugal: Porto Editora, 2007. p. 11-30.

RICOEUR, Paul. Tempo e narrativa 3. O tempo narrado. Tradução de Claudia Berliner. São Paulo: Editora WMF Martins Fontes, 2010.

SOUZA, Elizeu Clementino de. $\mathbf{O}$ conhecimento de si: estágio e narrativas de formação de professores. Rio de Janeiro: DP\&A; Salvador: EDUNEB, 2006.

SOUZA, Elizeu Clementino de; FORNARI, Liege Maria Sitja. Memória, (Auto)Biografia e Formação. In: VEIGA, Passos Alencastro; D’ÁVILA, Cristina Maria. (Orgs.). Profissão docente: novos sentidos, novas perspectivas. Campinas, SP: Papirus, 2012. p. 109134.

Recebido em: 10.01.2017

Aprovado em: 25.03.2017

Luiz Carlos Pinheiro Ferreira é Doutor em Arte e Cultura Visual pelo Programa de Pós-Graduação em Arte e Cultura Visual da UFG. Professor Adjunto e Coordenador do Curso de Licenciatura em Artes Visuais [Noturno] da Universidade de Brasília. e-mail: luizcpferreira@gmail.com

Universidade de Brasília - Campus Universitário Darcy Ribeiro - Bairro: Asa Norte - Brasília - Distrito Federal - 61 999144226 ou $61-34473082$ 